\title{
Expression of Bcl-2 genes in channel catfish after bacterial infection and hypoxia
}

\author{
stress
}

Zihao Yuan*, Shikai Liu*, Jun Yao, Qifan Zeng, Suxu Tan, Zhanjiang Liu ${ }^{\S}$

The Fish Molecular Genetics and Biotechnology Laboratory, Aquatic Genomics Unit,

School of Fisheries, Aquaculture and Aquatic Sciences and Program of Cell and

Molecular Biosciences, Auburn University, Auburn, AL 36849, USA

*These authors contributed equally to this work.

${ }^{\S}$ Corresponding author: 203 Swingle Hall, School of Fisheries, Aquaculture and

Aquatic Sciences, Auburn University, Auburn, AL 36849, USA; Tel.: 1-334-844-8727;

Fax: 1-334-844-9288; E-mail: liuzhan@ auburn.edu 


\section{Abstract:}

Bcl-2 proteins are of vital importance in regulation of apoptosis, and are involved in a number of biological processes such as carcinogenesis and immune responses. Bcl-2 genes have been well studied in mammals, while they are not well investigated in teleost fish including channel catfish, the major aquaculture species in the United States. In this study, we identified 34 bcl-2 genes from the channel catfish genome, and verified their identities by conducting phylogenetic and syntenic analyses. The expression profiles of the bcl-2 genes in response to bacterial infections (Edwardsiella ictaluri and Flavobacterium columnare) and hypoxia stress were determined by performing meta-analysis using the existing RNA-Seq datasets. Differential expressions of bcl-2 genes were observed after bacterial infections and hypoxia treatment, including 22 bcl-2 genes after $E$. ictaluri infection, 22 bcl-2 genes after $F$. columnare infection, and 19 bcl-2 genes after hypoxia stress. Overall, the expression of the pro-apoptotic bcl-2 genes were repressed after bacterial infection and hypoxia stress, indicating that bcl-2 genes are potentially involved in the stress response by reducing cell apoptosis. Some bcl-2 genes, such as bcl2b, mcl1a, bmf1, and bnip3, showed different expression pattern during the E. ictaluri and F. columnare infection, suggesting the difference in the pathogenicity of diseases. This work presented the first systematic identification and annotation of bcl-2 genes in catfish, providing essential genomic resources for further immune and physiological studies.

Keywords: Bcl-2; Genome; Expression; Disease; Hypoxia; Fish 


\section{Introduction}

Bcl-2 proteins are a family of regulatory proteins that regulate cell apoptosis by either inducing or repressing cell death. They are involved in the intrinsic pathway of caspase-dependent apoptosis (Kratz et al., 2006). Based on their functions and homology motifs, the bcl-2 family proteins are generally divided into three categories, including the pro-apoptotic $\mathrm{BH} 3$-only proteins, the multidomain anti-apoptotic proteins, and the multidomain pro-apoptotic proteins. The apoptotic stimuli such as stress activate the pro-apoptotic $\mathrm{BH} 3$-only proteins, which antagonize the multidomain anti-apoptotic proteins, preventing them from blocking the functions of the multidomain pro-apoptotic proteins (Willis and Adams, 2005). Moreover, the pro-apoptotic $\mathrm{BH} 3$-only proteins can directly activate the multidomain pro-apoptotic proteins by forming the heterodimers (Letai et al., 2002). Consequently, the activated multidomain pro-apoptotic proteins punch the outer membrane of the mitochondrial and release cytochrome $\mathrm{C}$ to trigger the downstream caspase cascades in the cell (Green and Kroemer, 2004). Remarkably, in some cells, a pro-apoptotic BH3-only protein "bid" can also be activated by the caspase- 8 from the extrinsic pathway, making it a converging point for the extrinsic and intrinsic pathway (Yin et al., 1999).

Bcl-2 genes have been well studies in mammals because of their important roles in apoptosis, and their involvement in numerous cancer diseases (Gascoyne et al., 1997; Gobé et al., 2002; Han et al., 2002; Hardwick and Soane, 2013; Hindy et al., 2011; Ola et al., 2011). Various studies conducted in humans indicated that bcl-2 
genes are actively involved in the host immune response after the bacterial infection by regulating the process of apoptosis in the organism (Casalino-Matsuda et al., 2015; Liston et al., 2003; Vazquez and Colombo, 2010). In addition, previous studies indicated that the hypoxia activated cardiac death through the pro-apoptotic bcl-2 gene (Kubasiak et al., 2002), meanwhile the anti apoptotic bcl-2 genes effectively retarded the chemical hypoxia-induced necrotic cell death (Shimizu et al., 1996). Therefore, it is highly likely that the bcl-2 genes play critical roles in the stress response by regulating the process of apoptosis. In teleost fish, the bcl-2 family genes have not been well studied, including species that whole genomes have been sequenced and annotated.

Catfish is the major aquaculture species in the United States (Liu et al., 2011). In recent years, the catfish industry has been greatly hindered by frequent pond stresses such as devastating diseases. The most significant diseases in channel catfish are the enteric septicemia of catfish (ESC) caused by Edwardsiella ictaluri (Hawke et al., 1981), and columnaris disease caused by Flavobacterium columnare (Shoemaker et al., 2008). The incidents of these diseases are increased by stress such as exposure to hypoxic conditions. As apoptosis is a universal response to all stressors, the study of apoptosis is of vital importance in understanding host stress response mechanisms after stress. Previous studies have reported some apoptosis related genes including HSP proteins (Weber and Janz, 2001; Song et al., 2014; 2016; Xie et al., 2015), tumor necrosis factor (Zou et al., 2003), FasL-like protein (Long et al., 2004) and tumor 
suppressor genes (Mu et al., 2015) in channel catfish. A previous study has observed that the apoptosis would decrease in the presence of confinement stress in channel catfish (Alford Iii et al., 1994). However, studies of bcl-2 genes in relationship with other stress such as bacterial infections and hypoxia remain unexplored in channel catfish. In this study, with the objective to identify and annotate bcl-2 genes in the channel catfish genome, and understand their roles in response to disease infections and hypoxia stress, we performed a comprehensive genome-wide identification and annotation of bcl-2 genes in channel catfish, and characterized their expression profiles after infections of E. ictaluri and F. columnare, and after hypoxia stresses.

\section{Materials and methods}

\subsection{Database mining and sequence analysis}

To identify the bcl-2 genes in channel catfish, based on the references (Eimon and Ashkenazi, 2010; Hardwick and Soane, 2013; Kratz et al., 2006; Ola et al., 2011; Siddiqui et al., 2015), all available bcl-2 protein sequences from human, mouse, dog, chicken, frog and teleosts including (Astyanax mexicanus, Danio rerio, Esox lucius, Gadus morhua, Larimichthys crocea, Lepisosteus oculatus, Takifugu rubripes, Tetraodon nigroviridis, Poecilia formosa, Scleropages formosus) were retrieved from public databases such as NCBI database (http://www.ncbi.nlm.nih.gov/) and ENSEMBL genome browser (http://www.ensembl.org/), and were used as queries to search against channel catfish transcriptome databases (Li et al. 2012; Sun et al. 2012; 
Liu et al. 2012) via TBLASTN, the E-value was set to $1 \mathrm{e}-5$ to ensure the quality of the searching results. The BLASTN was used to verify the cDNA sequences through comparing the transcriptome sequence with genome sequences (Liu et al. 2016). The homologous sequences identified from the channel catfish were then extracted for further annotation. The open reading frames (ORFs) were predicted using the ORF Finder (http://www.ncbi.nlm.nih.gov/gorf/gorf.html), followed by further verification using BLASTP against NCBI non-redundant protein database.

\subsection{Phylogenetic and syntenic analysis}

Phylogenetic analyses were conducted using bcl-2 genes identified from channel catfish together with those from other species including human, mouse, chicken, frog and several teleost fish. Multiple alignments of protein sequences were conducted by MUSCLE (MUltiple Sequence Comparison by Log-Expectation) (Edgar, 2004) with default parameters. The phylogenetic tree was constructed using MEGA5.2.2 software (Tamura et al., 2011) with the maximum likelihood method. The best model (Figures legend 1-4 ) was selected by Prottest 3.2.1 according to the alignment results (Darriba et al., 2011). The bootstrap of 1000 replications was conducted to evaluate the phylogenetic tree. To provide additional evidence of gene orthologies, syntenic analyses were conducted for bcl-2 members that are not well supported by the phylogenetic tree. The predicted channel catfish bcl-2 protein sequences were searched against the channel catfish genome assembly, followed by the extraction of 
the genomic scaffolds and linkage groups that the channel catfish bcl-2 genes are located. The gene prediction of the genomic sequences was conducted using the FGENESH program (Solovyev et al., 2006). The conserved syntenic blocks near these bcl-2 genes in other species were based on information from Genomicus (Louis et al., 2012; Louis et al., 2015), NCBI database (http://www.ncbi.nlm.nih.gov/) and ENSEMBL genome browser (http://www.ensembl.org/).

\subsection{Expression analysis of bcl-2 following stress challenges}

Meta-analyses of RNA-Seq datasets were conducted to determine the expression profiles of bcl-2 genes in response to bacterial infections (E. ictaluri and F. columnare) and hypoxia stress. The stress challenges were conducted as previously described (Li et al. 2012; Sun et al. 2012; Feng et al. 2013). Briefly, the fish were challenged in six 30L aquatia with 3 control and 3 treatment groups for each challenge. The bacterial were isolated form symptomatic fish and biochemically confirmed before being inoculated in Brain Heart Infusion broth (BHI) and incubated in the shaker incubator overnight. The concentrations of bacteria were determined by colony forming unit (CFU) per mL by plating $10 \mu \mathrm{L}$ of 10 -fold serial dilutions onto $\mathrm{BHI}$ agar plates. For ESC challenge, $200 \mathrm{ml}$ E. ictaluri with a concentration of $4 \times 10^{8} \mathrm{CFU} / \mathrm{mL}$ was added into the treatment aquaria with the water flow turned off for $2 \mathrm{~h}$. Control fish were exposed to the same routine as treatment fish, except were immersed in sterilized media alone. At each sampling time-point of $4 \mathrm{~h}, 24 \mathrm{~h}$ and $3 \mathrm{~d}$ after infection, 30 fish were 
collected from the control and treatment aquaria and anesthetized with MS-222 (300 $\mathrm{mg} / \mathrm{L}$ ). The entire intestinal tracts intestine from 10 fish (3 replicates of 10 fish each) were pooled together for each tissue, flash frozen in liquid nitrogen and stored at $-80{ }^{\circ} \mathrm{C}$ until RNA extraction.

Similarly, F. columnare challenges were conducted with six $30 \mathrm{~L}$ aquaria of which three aquaria were used as control and the other three were used as challenge groups. $200 \mathrm{ml} \mathrm{F}$. columnare with a concentration of $3 \times 10^{6} \mathrm{CFU} / \mathrm{mL}$ were added into the treatment aquaria for $2 \mathrm{~h}$. Gills of 18 fish were collected and randomly divided into three replicate pools (6 fish each) at each sampling time point: $4 \mathrm{~h}, 24 \mathrm{~h}, 48 \mathrm{~h}$. Samples were flash-frozen in liquid nitrogen and stored at $-80{ }^{\circ} \mathrm{C}$ until RNA extraction.

For hypoxia challenge, 350 fish were acclimated in $90 \times 60 \times 30 \mathrm{~cm}(\mathrm{~L} \times \mathrm{W} \times \mathrm{H})$ tanks with flow-through water for a week. After acclimation, 50 fish were taken to another tank as control group, the remaining fish were exposed to hypoxia stress. Dissolve oxygen levels in the challenge groups were reduced from $8.50 \mathrm{mg} / \mathrm{L}$ to 1.00 $\mathrm{mg} / \mathrm{L}$ after bubbling nitrogen gas into the aquarium for $1.5 \mathrm{~h}$. The oxygen level was measured every hour and the oxygen concentration was properly maintained. Starting at $1.5 \mathrm{~h}$ when first fish started to lose balance, samples were collected continuously until 45 fish were collected. At $5 \mathrm{~h}$ after low oxygen challenge, 45 tolerant fish were randomly collected. 15 fish were collected for hypoxia resistance, hypoxia tolerant and control group and anesthetized with MS-222 (300mg/L), brain, gill, head kidney, heart, liver, muscle, spleen, stomach, swim bladder and trunk kidney samples are collected 
and pooled for RNA-seq analysis.

The RNA-Seq datasets for ESC (NCBI SRA no. SRP009069) were generated from samples collected from the intestine 3 hours, 24 hours and 3 days after $E$. ictaluri infection (Li et al., 2012). The RNA-Seq datasets for columnaris (NCBI SRA no. SRP012586) were generated from samples collected from the gill 4 hours, 24 hours and 48 hours after the F. columnare infection (Sun et al., 2012). The RNA-Seq datasets for hypoxia (NCBI SRA no. SRP039612) were generated from the samples collected from the gill of the channel catfish that were sensitive and resistant to hypoxia after hypoxia stress (Feng et al. 2013). Expression analyses using RNA-Seq datasets were conducted using CLC Genomics Workbench (v5.5.2). RNA-Seq reads were mapped to the reference transcripts with the parameters setting as at least $95 \%$ read length with a maximum of 2 mismatches. Then, Reads Per Kilobase of exon model (RPK) was calculated based on the number of total mapped reads of the bcl-2 genes and the housekeeping gene, beta-actin (actb). The expression value of each gene was determined based on the ratio of bcl-2 gene RPK to that of the actb in the same sample. Differential expression in fold-change was determined based on the ratio of the expression value of each bcl-2 gene between control and challenged groups and unchallenged groups. Based on the previous work, the genes with absolute expression fold change value $\geqslant 1.5$ and total gene read $\geqslant 5$ were considered as genes that were significantly altered in expression after stress treatments. (Fu et al., 2016; Li et al., 2016; Xie et al., 2015) 


\section{Results}

\subsection{Identification of channel catfish bcl-2 genes}

A total of 34 bcl-2 genes were identified from the channel catfish genome. Their characteristics are summarized in Table 1, including their mammalian homologs, gene abbreviations, open reading frames, their genomic location in linkage groups and their accessions. These 34 bcl-2 genes included 22 pro-apoptotic BH3-only proteins (bada, badb, bid, bik, bim, bmf1, bmf2, pmaip1, puma, bcl2114 (1 of 2), bcl2114 (2 of 2), bc121151, bc12113, bnip1a, bnip1b, bnip2a, bnip2b, bnip2c, bnip21, Bnip3, bnip31a, bnip3lb), 7 multidomian anti-apoptotic proteins (mcl1a, mcl1b, blp1, bcl2a, bcl2b, bcl2110, bcl2112), and 5 multidomain pro-apoptotic proteins (baxa, baxb, baxl, bok, bcl2116). These bcl-2 genes shared a relatively high level of sequence similarity with their mammalian counterparts. All these sequences have been submitted to GenBank and their accession numbers are provided in Table 1. The bad, bmf, bcl2114, bnip1, mcl and bcl-2 each possessed 2 copies, the bnip3 and bax each had three copies, whereas bnip2 had four copies (Table 1).

\subsection{Phylogenetic analysis of channel catfish bcl-2 genes}

Phylogenetic analysis was conducted to determine the identities of the channel catfish bcl-2 genes. Although the bcl-2 genes are divided into three major categories as mentioned above, in consistence with previous studies on phylogenomics of bcl-2 gene families (Aouacheria et al., 2005), we separated the bnips (bnip1, bnip2, bnip3) 
from the subfamily of the $\mathrm{BH} 3$-only proteins to construct the phylogenetic tree, because the bnip genes were an atypical subfamily in the pro-apoptotic $\mathrm{BH} 3$-only proteins. Bnips possess some of unique characteristics such as interaction with the adenovirus E1B $19 \mathrm{kDa}$ protein, which is an anti-apoptotic protein (Boyd et al., 1994).

Phylogenetic trees were constructed for each of the four classes of bcl-2 genes (Figures 1-4), in general, catfish bcl-2 genes within each family were clustered with their counterparts from human and zebrafish, respectively. As shown in Figure 1, 7 pro-apoptotic BH3-only proteins (bada, bik, bim, bmf1, bmf2, pmaip1, puma) were clustered into the proper clades with their counterparts from zebrafish, bcl2115 fell into the proper clade with its counterpart with bcl 21151 from cavefish. Of the 9 bnip proteins, 3 (bnip1a, bnip3la, bnip31b) fell into the proper clade with their counterparts from zebrafish (Figure 2). Of the 7 multidomain anti-apoptotic proteins, 4 (mcl1a, mcl1b, blp1, bcl2110) of them fell into proper clades with their counterparts from zebrafish (Figure 3). Of the 5 multidomain pro-apoptotic proteins, 3 (baxa, baxb, bok) fell into proper clades with their counter parts from zebrafish (Figure 4). The putative channel catfish genes, including badb, bid, bcl2113, bcl2114s, bnip1b, bnip2s, bnip3, bcl2s, bcl2112, one copy of bax on linkage group 3 and bcl2116 did not form a well-defined cluster with that in zebrafish, and therefore the syntenic analysis requires to be conducted to verify their identities. 


\subsection{Syntenic analysis of channel catfish bcl-2 genes}

Phylogenetic analysis alone did not allow concrete annotation for several of the bcl2 genes, and therefore, syntenic analysis was conducted to provide insights into orthologies. Syntenic analysis of several bcl-2 genes including badb, bid, bcl2113, bcl2114s, bnip1b, bnip2s, bnip3, bcl2s, bcl2112, a copy of bax on linkage group 3 and bcl2116 were conducted as shown in Figure 5. Apparently, conserved synteny regions were found between channel catfish and other species for badb (Fig. 5A), bid (Fig. 5B), bcl2113 (Fig. 5B), bcl2114s (Fig. 5C), bnip1b (Fig. 5D), bnip2s (Fig. 5E), bnip3 (Fig. 5F), bcl2s (Fig. 5G), blc2112 (Fig. 5H), and bcl2116 (Fig. 5I). For badb, the zebrafish and channel catfish has the same group of neighboring genes such as b3gat3, ar12, ppp2r5b gpha2, exoc6b and cyp26b1.

For bid, bcl2113 genes were neighboring genes in human, zebrafish and channel catfish while they were located between cftr and rapsn in zebrafish and channel catfish. Two copies of the bc12114 genes were identified in cavefish and channel catfish, and they shared the conserved neighboring genes with that of zebrafish, respectively. The bcl2114 (1 of 2) in channel catfish and cavefish shared the neighboring genes of tbc1d15, chrf8, and has3, the bcl2114(2 of 2) in channel catfish and cavefish shared the neighboring genes of rassf3 and dgki (Figure 5C). The bnip $1 \mathrm{~b}$ in channel catfish and zebrafish shared conserved neighboring genes of crebrf, stc $2 b$ and bod1 (Figure 5D). The copies of bnip2 on LG18, LG14, LG2 shared at least one of the neighboring genes including dnaja4, otud7a, klf13, trpm1 and cib with those in 
zebrafish. For one copy of bnip2 on scaffold jcf7180014891172, the neighboring genes were not conserved between channel catfish and zebrafish. Due to the lack of evidence for conserved synteny, we named the channel catfish bnip2 gene on LG7 as "bnip2-like". Meanwhile, the bnip3 gene in channel catfish shared the gene of dpys14 and jakmip3 with that in zebrafish (Figure 5F). The bcl2a gene in channel catfish and zebrafish has the same neighboring genes of fbxo, prkag2, hs6st1b and ek1. In addition, channel catfish bcl2b is located between vps $4 b$, kdsr and prkag2 in the genomes, which was consistent with that of zebrafish (Figure 5G). The channel catfish bcl2112 gene shared the same neighboring genes with that in zebrafish such as pax, tspan4b, unc119.2 and srrm2 (Figure 5H). The bcl2116 gene in channel catfish on LG8 shared the neighboring genes of nr6a1a, nr5a1a, adgrd2 and tubb2b with that in zebrafish. (Figure 5I). Moreover, we were not able to identify conserved synteny blocks of the bax on LG3 in catfish with that in zebrafish, thus we named it as baxl. Taken together, the syntenic analysis provided sufficient evidence for the annotation and nomenclature of the bcl-2 genes in channel catfish.

\subsection{Expression of bcl-2 genes after bacterial infection}

Expression profiles of bcl-2 genes after bacterial infections with two pathogens, $E$. ictaluri and $F$. columnare were determined using the available RNA-Seq datasets. Following the meta-analysis, the bcl-2 genes that potentially exhibited differential expression were identified. Of the 34 bcl- 2 genes, 29 were differentially expressed 
after bacterial infections, with 22 genes being differentially expressed after $E$. ictaluri infection and 22 genes being differentially expressed after $F$. columnare infection. As shown in Fig. 6, after E. ictaluri infection, 13 genes (bada, badb, bik, pmaip1, bcl2114 (1 of 2), bcl2114 (2 of 2), bcl2113, bcl21151, bnip1b, mcl1a, bcl2110, baxa, baxl) were down-regulated and 9 genes (bmf1, bnip2a, bnip2b, bnip2c, bnip3, bnip3la, bcl2a, bcl2b, baxb) were up-regulated. The numbers of down-regulated genes increased during the infection progress, from 6 genes at 3 hours (badb, bik, bcl2114(1 of 2), bcl2114(2 of 2), mcl1a, baxl) to 12 genes at 72 hours (bada, badb, bik, pmaip1, bcl2114(1 of 2), bcl2114(2 of 2), bcl21151, bcl2113, bnip1b, bcl2110, baxa, baxl) after infection. The number of up-regulated genes decreased from 7 to 5 and to 4 through the period of 3 hours (bmf1, bnip2a, bnip2c, bnip3, bnip3la, bcl2a, baxb), 24 hours (bmf1, bnip2b, bnip31a, bcl2a, bcl2b) and 72 hours (bnip2b, bnip2c, bnip3la, bcl2a) after infection.

The expression of bcl-2 genes exhibited a different pattern after $F$. columnare infection. (Fig. 7.) Among the 16 constantly down-regulated genes (bada, bik, bmf1, puma, bcl2114 (1 of 2), bcl2114 (2 of 2), bcl2113, bnip3, bnip3lb, bnip3la, bcl2b, bcl2110, bcl2112, baxa, baxl, bcl2116), 15 (bada, bik, bmf1, puma, bcl2114 (1 of 2), bcl2114 (2 of 2), bnip3, bnip3lb, bnip3la, bcl2b, bcl2110, bcl2112, baxa, baxl, bcl2116) were repressed 24 hours after infection. The expression of up-regulated genes showed a more modest pattern, with three genes (blp1, mcl1a, baxb) up-regulated 4 hours after infection, bnipla were up-regulated 24 hours while badb and bid are 
up-regulated 48 hours after infection.

\subsection{Expression of bcl-2 genes after hypoxia challenge}

The expression of bcl-2 genes in response to hypoxia stress was conducted among groups of fish with different levels of hypoxia tolerance. Pairwise comparison was conducted among groups with different hypoxia tolerance, i.e., tolerant vs control, sensitive vs control, and tolerant vs sensitive. A total of 19 genes were significantly differentially expressed after hypoxia stress, including 14 genes that were significantly regulated in the tolerant group as compared with the control group. Among them, eight genes (badb, pmaip1, bcl2113, bnip1b, bnip2b, blp1, bcl2110, baxl) were induced, while six genes (bik, bnip1a, bnip2a, bcl2a, baxa, bok) were suppressed under hypoxia conditions. The comparison between sensitive and control group revealed that pmaip1, mcl1a and bcl2110 were up-regulated at higher level in sensitive than in control group, and bid, bik, bmf1, puma, bnip2b and bnip2c were expressed in lower levels in sensitive group than those in control group (Fig. 8).

The comparison between tolerant group and sensitive group revealed that four genes were significantly differentially expressed between the groups (Figure 8). After hypoxia challenge, pmaip1 and bcl2110 were expressed at higher levels in hypoxia tolerant group than those in sensitive group. Similarly, the expression of bik decreased less in hypoxia tolerant group than that in sensitive group; and the expression of bnip $2 b$ decreased in hypoxia sensitive fish but increased in hypoxia tolerant fish. 


\section{Discussion}

The bcl-2 genes are important in the regulation of apoptosis. Although bcl-2 have been observed to be expressed in a multitude of tissue types in channel catfish (Chen et al., 2010; Zeng et al., 2016), a comprehensive analysis of bcl-2 genes in channel catfish is lacking. In this study, we conducted systematic analysis of channel catfish bcl-2 gene family and identified a total of 34 bcl-2 genes in channel catfish genome. The analysis phylogeny and synteny allowed annotation of these bcl-2 genes. The 34 bcl-2 genes in channel catfish include 22 pro-apoptotic $\mathrm{BH} 3$-only proteins, seven multidomain anti-apoptotic proteins and five multidomain pro-apoptotic proteins. Furthermore, for the first time, the expression profiling of $34 \mathrm{bcl}-2$ genes after bacterial infection and hypoxia challenge were determined to provide insight into their involvement in the stress response. A number of bcl-2 genes differentially expressed after stress treatments were identified; and different expression patterns were observed between bacterial infections and hypoxia stress, and between the two different bacterial infections.

The phylogenetic and syntenic analysis verified the gene identities, and facilitated the annotation of duplicated genes. The analysis of copy numbers of bcl-2 genes in teleost fish and several other model species suggested that the copy numbers of bcl-2 genes were generally conserved across species (Table 1). However, teleost fish such as channel catfish, zebrafish and cavefish had more copies of several bcl-2 genes than 
those in the reptile, bird and mammals. Syntenic analysis indicated that expansion of these genes could be related to fish-specific whole genome duplication (Meyer and Van de Peer, 2005). For the duplicated gene bax, two copies of bax genes in channel catfish were both on scaffold jcf7180014892032, which is consistent with the observation in zebrafish in which the baxa and baxb were both on chromosome 3 . Besides the teleost-specific duplication of bcl-2 genes, we identified bcl2116, which involves the controlling of cell migration during gastrulation (Prudent et al., 2014). $\mathrm{Bcl} 2116$ is unique to channel catfish, zebrafish and cavefish. The loss or duplication of genes during the fish-specific whole genome duplication 226-350 Myr ago (Hurley et al., 2007) may account for the various gene copies in different species in the subgroup of bnips, the loss of bcl2115 in zebrafish and the loss of bim and pmaip1 in cavefish.

The channel catfish production has been severely impacted by bacterial diseases such as the enteric septicemia of catfish (ESC) (Hawke et al., 1998), columnaris disease (Bader and Starliper, 2002) and low oxygen stress. In the present study, we determined the expression profile of bcl-2 genes after E. ictaluri and $F$. columnare infection, and hypoxia challenges. As for E. ictaluri challenge, 15 pro-apoptotic BH3-only proteins (bada, badb, bik, bmf1, pmaip1, bcl2114 (1 of 2), bcl2114 (2 of 2), bc121151, bc12113, bnip1b, bnip2a, bnip2b, bnip2c, bnip3, bnip3la), four multidomain anti-apoptotic proteins (bcl2a, bcl2b, mcl1a, bcl2110) and three multidomain pro-apoptotic proteins (baxa, baxb, baxl) were significantly changed in the expression after E. ictaluri challenge (Fig. 6). Thirteen pro-apoptotic BH3-only proteins (bada, 
badb, bid, bik, bmf1, puma, bcl2114 (1 of 2), bcl2114 (2 of 2), bcl2113, bnip1a, bnip3, bnip3la, bnip3lb), five multidomain anti-apoptotic proteins (blp1, bcl2b, mcl1a, bcl2110, bcl2112) and four multidomain pro-apoptotic proteins (baxa, baxb, baxl, bcl2116) were significantly differently expressed after $F$. columnare infection (Fig. 7). The expression of multidomain pro-apoptotic proteins and pro-apoptotic BH3-only proteins were generally decreased after both E. ictaluri and F. columnare infection, suggesting the bacterial infection, like confinement stress (Alford lii et al., 1994), triggered regulated expression of the bcl-2 family genes in channel catfish to decrease the apoptosis rate of cells.

Different patterns of expression of bcl-2 genes were observed between the two bacterial infections. After $F$. columnare infection, most of the differentially expressed genes showed a down-regulation observed at the 24 hours after infection. However, after the E. ictaluri infection, the differential expression of most genes was observed at the 72 hours after infection. This discrepancy could be attributed to the differences in pathogenicity of the E. ictaluri and the F. columnare.

Interestingly, several genes exhibited an opposite expression pattern between the E. ictaluri infection and the $F$. columnare infection. These included bnip3, bcl2b, mcl1a and bmf1 (Figs. 6 and 7). The bnip3 and bcl2b were up-regulated after $E$. ictaluri infection while they were down-regulated after $F$. columnare infection. The altered expression of bnip3 was observed in tumor like prostatic carcinoma, lung cancer, endometrium cancer and breast cancer (Li and Sheng, 2014). The low 
expression of the pro-apoptotic bnip3 may contribute to the decreased expression of multidomain pro-apoptotic proteins like baxs and bcl2116 during the F. columnare infection. However, a study in neuron cells indicated that bnip3 was significantly up-regulated after ischemia (Li et al., 2013). Since the E. ictaluri infection can cause ischemia in channel catfish, the up-regulation of the bnip3 after E. ictaluri infection may be related to the ischemia. Bcl-2 is a well-studied oncogene. Overexpression of bcl-2 gene prevents neurons from apoptosis in the ischemia mice (Martinou et al., 1994). Similar to the expression pattern of bnip3, the high expression of the bcl2b after E. ictaluri infection may also be associated with the hemorrhages in intestine.

The down-regulated expression of mc11a was observed after E. ictaluri infection. In humans, mcl1 is critical for the survival of macrophages to battle against hemorrhages and inflation (Liu et al., 2006). Since a typical symptom of ESC disease is the serious hemorrhages and inflation, it's expected an increased expression of mc11a, which was opposite to the observation of this work. The mechanism of down-regulated mc11a expression after E. ictaluri infection in our study remains to be explained. The bmf1 was highly expressed after E. ictaluri infection, while its expression was suppressed during the $F$. columnare infection. Bmf was reported to trigger apoptosis (Frenzel et al., 2010). The mechanisms underlying the opposite expression of bmf after E. ictaluri and F. columnare deserves further investigation. Some in vitro systems such as cell lines can be used in the future to determine the roles of bcl-2 family members in the process of apoptosis. Channel catfish is the only 
fish species where clonal functionally distinct lymphocyte lines have been established (Clem et al., 1990,1996; Miller et al., 1998; Shen et al., 2001). Along with these lymphocyte cell lines, several other cell lines have been established from various tissues of channel catfish including ovaries (Bowser et al., 1980), leukocytes (Miller., 1994), monocytelike cells (Vallejo et al., 1991), kidney (Zeng et al., 2009) and lymphoid cells (Majji et al., 2009). Future investigation with these cell lines would allow determination of tissue specificity as well as the involvement of bcl-2 genes in apoptosis under various physiological conditions.

After hypoxia stress, 12 pro-apoptotic BH3-only proteins (badb, bid, bik, bmf1, pmaip1, puma, bc12113, bnip1a, bnip1b, bnip2a, bnip2b, bnip2c), four multidomain anti-apoptotic proteins (blp1, bcl2a, mcl1a, bcl2110), three multidomain pro-apoptotic proteins (baxa, baxl, bok) were found to be significantly differentially expressed after hypoxia challenge. Among the differentially expressed genes, the expression of 2 out of 3 multidomain pro-apoptotic bcl-2 genes were down-regulated, 3 out of 4 multidomain anti-apoptotic bcl-2 genes were induced, 7 out of 12 pro-apoptotic BH3-only bcl-2 genes were suppressed. In general, the increased expression of most multidomain anti-apoptotic bcl-2 genes and decreased expression of most pro-apoptotic BH3-only bcl-2 genes could be reason for the decreased expression of the multidomain pro-apoptotic bcl-2 genes, and thus repress the apoptosis process in channel catfish after stress (Alford Iii et al., 1994). 
The differentially expressed bcl-2 genes between the hypoxia tolerant and sensitive groups are of particular interest. The genes showing great differential expression may suggest their association with the hypoxia resistance in channel catfish. Two genes, blp1 (6.04 fold change) and bnip2b (6.57 fold change), were drastically higher expressed in hypoxia tolerant fish than those in the hypoxia sensitive fish. Although no previous study suggested any interactions between these two genes, protein interaction prediction by program GeneMANIA revealed the interactive relationship between the bnip2 and bcl211 (blp1) through bcl-2 (ENSDARG00000089109) (Fig. 9). Interestingly, from the predicted interaction pattern, blp1 and bnip2 also interact with other differentially expressed genes during the hypoxia challenge, including bcl2113, mcl1, bcl2110, baxa and bok, indicating a potential interactive networks formed by those bcl-2 genes that regulate the apoptosis process in response to hypoxia stress in channel catfish.

In summary, we, for the first time, identified and annotate a set of 34 bcl-2 genes in channel catfish. We further determined their expression profiles to gain insights into their putative roles in response to bacterial infection and hypoxia stress. After stress, most anti-apoptotic bcl-2 genes were significantly up-regulated, while most pro-apoptotic bcl-2 genes were significantly down-regulated, suggesting their involvement in the host response to stress by suppressing apoptosis process. Different expression pattern of bcl-2 genes during pathogenesis of two bacterial pathogens indicated the pathogen-specific pattern of regulation. However, the bcl-2 family 
contains a number of genes, which may interact and complement with each other to function and form a balanced regulation network of apoptosis in the cell.

\section{Acknowledgments}

This project was supported by a competitive grant from Agriculture and Food Research Initiative Animal Health Program 2015-67015-22975, and a competitive grant from USDA Aquaculture Research Program no. 2014-70007-22395, both from the USDA National Institute of Food and Agriculture (NIFA). We thank Data Intensive Academic Grid (DIAG) for providing the computing capacity for the bioinformatics analysis. Zihao Yuan was supported by a scholarship from the China Scholarship Council.

\section{Reference}

Alford Iii, P.B., Tomasso, J.R., Bodine, A.B., Kendall, C., 1994. Apoptotic death of peripheral leukocytes in channel catfish: effect of confinement-induced stress. Journal of Aquatic Animal Health 6, 64-69.

Aouacheria, A., Brunet, F., Gouy, M., 2005. Phylogenomics of life-or-death switches in multicellular animals: Bcl-2, BH3-Only, and BNip families of apoptotic regulators. Molecular Biology and Evolution 22, 2395-2416.

Bader, J.A., Starliper, C.E., 2002. The genera flavobacterium and flexibacter, Molecular diagnosis of salmonid diseases. Springer, pp. 99-139.

Bowser, P.R., Plumb, J.A., 1980. Fish cell lines: establishment of a line from ovaries of channel catfish. In vitro $16,365-368$.

Boyd, J.M., Malstrom, S., Subramanian, T., Venkatesh, L.K., Schaeper, U., Elangovan, B., D'Sa-Eipper, C., Chinnadurai, G., 1994. Adenovirus E1B 19 kDa and Bcl-2 
proteins interact with a common set of cellular proteins. Cell 79, 341-351.

Casalino-Matsuda, S.M., Nair, A., Beitel, G.J., Gates, K.L., Sporn, P.H.S., 2015. Hypercapnia inhibits autophagy and bacterial killing in human macrophages by increasing expression of Bcl-2 and Bcl-xL. The Journal of Immunology 194, 5388-5396.

Chen, F., Lee, Y., Jiang, Y., Wang, S., Peatman, E., Abernathy, J., Liu, H., Liu, S., Kucuktas, H., Ke, C., 2010. Identification and characterization of full-length cDNAs in channel catfish (Ictalurus punctatus) and blue catfish (Ictalurus furcatus). PLoS One 5, e11546.

Clem, L.W., Bly, J.E., Ellsaesser, C.F., Lobb, C.J., Miller, N.W., 1990. Channel catfish as an unconventional model for immunological studies. Journal of Experimental Zoology 256, 123-125.

Clem, L., Bly, J., Wilson, M., Chinchar, V., Stuge, T., Barker, K., Luft, C., Rycyzyn, M., Hogan, R., Van Lopik, T., 1996. Fish immunology: the utility of immortalized lymphoid cells - a mini review. Veterinary immunology and immunopathology 54, 137-144.

Darriba, D., Taboada, G.L., Doallo, R., Posada, D., 2011. ProtTest 3: fast selection of best-fit models of protein evolution. Bioinformatics 27, 1164-1165.

Edgar, R.C., 2004. MUSCLE: multiple sequence alignment with high accuracy and high throughput. Nucleic Acids Research 32, 1792-1797.

Eimon, P.M., Ashkenazi, A., 2010. The zebrafish as a model organism for the study of apoptosis. Apoptosis 15, 331-349.

Feng, J., 2013. Transcriptome and expression profiling of response to acute hypoxia in the gill of adult catfish. Plant and Animal Genome XXI Conference, San Diego, CA.

Frenzel, A., Labi, V., Chmelewskij, W., Ploner, C., Geley, S., Fiegl, H., Tzankov, A., Villunger, A., 2010. Suppression of B-cell lymphomagenesis by the BH3-only proteins Bmf and Bad. Blood 115, 995-1005.

Fu, Q., Li, Y., Yang, Y., Li, C., Yao, J., Zeng, Q., Qin, Z., Liu, S., Li, D., Liu, Z., 2016. Septin genes in channel catfish (Ictalurus punctatus) and their involvement in disease defense responses. Fish \& Shellfish Immunology 49, 110-121. 
Gascoyne, R.D., Adomat, S.A., Krajewski, S., Krajewska, M., Horsman, D.E., Tolcher, A.W., O'Reilly, S.E., Hoskins, P., Coldman, A.J., Reed, J.C., 1997. Prognostic significance of Bcl-2 protein expression and Bcl-2 gene rearrangement in diffuse aggressive non-Hodgkin's lymphoma. Blood 90, 244-251.

Gobé, G., Rubin, M., Williams, G., Sawczuk, I., Buttyan, R., 2002. Apoptosis and expression of Bcl-2, Bcl-XL, and Bax in renal cell carcinomas. Cancer Investigation 20, 324-332.

Green, D.R., Kroemer, G., 2004. The pathophysiology of mitochondrial cell death. Science 305, 626-629.

Han, H., Landreneau, R.J., Santucci, T.S., Tung, M.Y., Macherey, R.S., Shackney, S.E., Sturgis, C.D., Raab, S.S., Silverman, J.F., 2002. Prognostic value of immunohistochemical expressions of p53, HER-2/neu, and bcl-2 in stage I nonsmall-cell lung cancer. Human Pathology 33, 105-110.

Hardwick, J.M., Soane, L., 2013. Multiple functions of BCL-2 family proteins. Cold Spring Harbor perspectives in biology 5, a008722.

Hawke, J.P., Durborow, R.M., Thune, R.L., Camus, A.C., 1998. ESC: enteric septicemia of catfish. Southern Regional Aquaculture Center Stoneville, Mississippi.

Hawke, J.P., McWhorter, A.C., Steigerwalt, A.G., Brenner, D.J., 1981. Edwardsiella ictaluri sp. nov., the causative agent of enteric septicemia of catfish. International Journal of Systematic Bacteriology 31, 396-400.

Hindy, N.E., Bachmann, H.S., Lambertz, N., Adamzik, M., Nückel, H., Worm, K., Zhu, Y., Sure, U., Siffert, W., Sandalcioglu, I.E., 2011. Association of the CC genotype of the regulatory BCL2 promoter polymorphism (-938C>A) with better 2-year survival in patients with glioblastoma multiforme: Clinical article. Journal of Neurosurgery 114, 1631-1639.

Hurley, I.A., Mueller, R.L., Dunn, K.A., Schmidt, E.J., Friedman, M., Ho, R.K., Prince, V.E., Yang, Z., Thomas, M.G., Coates, M.I., 2007. A new time-scale for ray-finned fish evolution. Proceedings of the Royal Society of London B: Biological Sciences 274, 489-498.

Kratz, E., Eimon, P.M., Mukhyala, K., Stern, H., Zha, J., Strasser, A., Hart, R., Ashkenazi, A., 2006. Functional characterization of the Bcl-2 gene family in the 
zebrafish. Cell Death \& Differentiation 13, 1631-1640.

Kubasiak, L.A., Hernandez, O.M., Bishopric, N.H., Webster, K.A., 2002. Hypoxia and acidosis activate cardiac myocyte death through the Bcl-2 family protein BNIP3. Proceedings of the National Academy of Sciences 99, 12825-12830.

Letai, A., Bassik, M.C., Walensky, L.D., Sorcinelli, M.D., Weiler, S., Korsmeyer, S.J., 2002. Distinct BH3 domains either sensitize or activate mitochondrial apoptosis, serving as prototype cancer therapeutics. Cancer cell 2, 183-192.

Li, C., Guan, T., Chen, X., Li, W., Cai, Q., Niu, J., Xiao, L., Kong, J., 2013. BNIP3 mediates pre-myelinating oligodendrocyte cell death in hypoxia and ischemia. Journal of Neurochemistry 127, 426-433.

Li, C., Zhang, Y., Wang, R., Lu, J., Nandi, S., Mohanty, S., Terhune, J., Liu, Z., Peatman, E., 2012. RNA-seq analysis of mucosal immune responses reveals signatures of intestinal barrier disruption and pathogen entry following Edwardsiella ictaluri infection in channel catfish, Ictalurus punctatus. Fish \& Shellfish Immunology 32, 816-827.

Li, J., Sheng, S., 2014. Research advancement on BNIP3 in regulating tumor cell autophagy and death. Journal of Clinical and Pathological Research 34, 779-785.

Li, Z., Yao, J., Xie, Y., Geng, X., Liu, Z., 2016. Phosphoinositide 3-kinase family in channel catfish and their regulated expression after bacterial infection. Fish \& Shellfish Immunology 49, 364-373.

Liston, P., Fong, W.G., Korneluk, R.G., 2003. The inhibitors of apoptosis: there is more to life than Bcl2. Oncogene 22, 8568-8580.

Liu, H., Huang, Q., Shi, B., Eksarko, P., Temkin, V., Pope, R.M., 2006. Regulation of Mcl-1 expression in rheumatoid arthritis synovial macrophages. Arthritis \& Rheumatism 54, 3174-3181.

Liu, S., Zhang, Y., Zhou, Z., Waldbieser, G., Sun, F., Lu, J., Zhang, J., Jiang, Y., Zhang, H., Wang, X., 2012. Efficient assembly and annotation of the transcriptome of catfish by RNA-Seq analysis of a doubled haploid homozygote. BMC Genomics 13, 595.

Liu, S., Zhou, Z., Lu, J., Sun, F.,Wang, S., Liu, H., et al., 2011. Generation of genome-scale gene-associated SNPs in catfish for the construction of a high-density SNP array. BMC Genomics 12, 53.

Liu, Z., Liu, S., Yao, J., Bao, L., Zhang, J., Li, Y., Jiang, C., Sun, L., Wang, R., Zhang, 
Y., 2016. The channel catfish genome sequence provides insights into the evolution of scale formation in teleosts. Nature Communications 7, 11757.

Long, S., Wilson, M., Bengtén, E., Clem, L.W., Miller, N.W., Chinchar, V.G., 2004. Identification and characterization of a FasL-like protein and cDNAs encoding the channel catfish death-inducing signaling complex. Immunogenetics 56, 518-530.

Louis, A., Muffato, M., Crollius, H.R., 2012. Genomicus: five genome browsers for comparative genomics in eukaryota. Nucleic Acids Research, gks1156.

Louis, A., Nguyen, N.T.T., Muffato, M., Crollius, H.R., 2015. Genomicus update 2015: KaryoView and MatrixView provide a genome-wide perspective to multispecies comparative genomics. Nucleic Acids Research 43, D682-D689.

Majji, S., Thodima, V., Arnizaut, A., Deng, Y., May, W., Sittman, D., Waldbieser, G., Hanson, L., Cuchens, M., Bengten, E., 2009. Expression profiles of cloned channel catfish (Ictalurus punctatus) lymphoid cell lines and mixed lymphocyte cultures. Developmental \& Comparative Immunology 33, 224-234.

Martinou, J.-C., Dubois-Dauphin, M., Staple, J.K., Rodriguez, I., Frankowski, H., Missotten, M., Albertini, P., Talabot, D., Catsicas, S., Pietra, C., 1994. Overexpression of BCL-2 in transgenic mice protects neurons from naturally occurring cell death and experimental ischemia. Neuron 13, 1017-1030.

Meyer, A., Van de Peer, Y., 2005. From 2R to 3R: evidence for a fish-specific genome duplication (FSGD). Bioessays 27, 937-945.

Miller, N.W., Chinchar, V.G., Clem, L.W., 1994. Development of leukocyte cell lines from the channel catfish (Ictalurus punctatus). Journal of Tissue Culture Methods 16, 117-123.

Miller, N., Wilson, M., Bfufltén, E., Stuge, T., Warr, G., Ciem, W., 1998. Functional and molecular characterization of teleost leukocytes. Immunological Reviews $166,187-197$.

Mu, W., Yao, J., Zhang, J., Liu, S., Wen, H., Feng, J., Liu, Z., 2015. Expression of tumor suppressor genes in channel catfish after bacterial infections. Developmental \& Comparative Immunology 48, 171-177.

Ola, M.S., Nawaz, M., Ahsan, H., 2011. Role of Bcl-2 family proteins and caspases in the regulation of apoptosis. Molecular and Cellular Biochemistry 351, 41-58. 
Prudent, J., Gillet, G., Popgeorgiev, N., 2014. Nrz but not zBcl-xL antagonizes Bcl-wav pro-apoptotic activity in zebrafish. Communicative \& Integrative Biology 7, e28008.

Shen, L., Stuge, T.B., Zhou, H., Khayat, M., Barker, K.S., Quiniou, S.M., Wilson, M., Bengtén, E., Chinchar, V.G., Clem, L.W., 2002. Channel catfish cytotoxic cells: a mini-review. Developmental \& Comparative Immunology 26, 141-149.

Shimizu, S., Eguchi, Y., Kamiike, W., Waguri, S., Uchiyama, Y., Matsuda, H., Tsujimoto, Y., 1996. Retardation of chemical hypoxia-induced necrotic cell death by Bcl-2 and ICE inhibitors: possible involvement of common mediators in apoptotic and necrotic signal transductions. Oncogene 12, 2045-2050.

Shoemaker, C.A., Olivares-Fuster, O., Arias, C.R., Klesius, P.H., 2008.

Flavobacterium columnare genomovar influences mortality in channel catfish (Ictalurus punctatus). Veterinary Microbiology 127, 353-359.

Siddiqui, W.A., Ahad, A., Ahsan, H., 2015. The mystery of BCL2 family: Bcl-2 proteins and apoptosis: an update. Archives of Toxicology 89, 289-317.

Solovyev, V., Kosarev, P., Seledsov, I., Vorobyev, D., 2006. Automatic annotation of eukaryotic genes, pseudogenes and promoters. Genome Biology 7, S10.

Song, L., Zhang, J., Li, C., Yao, J., Jiang, C., Li, Y., Liu, S., Liu, Z., 2014. Genome-wide identification of Hsp40 genes in channel catfish and their regulated expression after bacterial infection. PloS one 9, e115752..

Song, L., Li, C., Xie, Y., Liu, S., Zhang, J., Yao, J., Jiang, C., Li, Y., Liu, Z., 2016. Genome-wide identification of Hsp70 genes in channel catfish and their regulated expression after bacterial infection. Fish \& Shellfish Immunology 49, 154-162.

Sun, F., Peatman, E., Li, C., Liu, S., Jiang, Y., Zhou, Z., Liu, Z., 2012. Transcriptomic signatures of attachment, NF- $\kappa \mathrm{B}$ suppression and IFN stimulation in the catfish gill following columnaris bacterial infection. Developmental \& Comparative Immunology 38, 169-180.

Tamura, K., Peterson, D., Peterson, N., Stecher, G., Nei, M., Kumar, S., 2011. MEGA5: molecular evolutionary genetics analysis using maximum likelihood, evolutionary distance, and maximum parsimony methods. Molecular Biology and Evolution 28, 2731-2739. 
Vallejo, A.N., Ellsaesser, C.F., Miller, N.W., Clem, L.W., 1991. Spontaneous development of functionally active long-term monocytelike cell lines from channel catfish. In Vitro Cellular \& Developmental Biology-Animal 27, 279-286.

Vazquez, C.L., Colombo, M.I., 2010. Coxiella burnetii modulates Beclin 1 and Bcl-2, preventing host cell apoptosis to generate a persistent bacterial infection. Cell Death \& Differentiation 17, 421-438.

Weber, L.P., Janz, D.M., 2001. Effect of $\beta$-naphthoflavone and dimethylbenz [a] anthracene on apoptosis and HSP70 expression in juvenile channel catfish (Ictalurus punctatus) ovary. Aquatic Toxicology 54, 39-50.

Willis, S.N., Adams, J.M., 2005. Life in the balance: how BH3-only proteins induce apoptosis. Current Opinion in Cell Biology 17, 617-625.

Xie, Y., Song, L., Weng, Z., Liu, S., Liu, Z., 2015. Hsp90, Hsp60 and sHsp families of heat shock protein genes in channel catfish and their expression after bacterial infections. Fish \& Shellfish Immunology 44, 642-651.

Yin, X.-M., Wang, K., Gross, A., Zhao, Y., Zinkel, S., Klocke, B., Roth, K.A., Korsmeyer, S.J., 1999. Bid-deficient mice are resistant to Fas-induced hepatocellular apoptosis. Nature 400, 886-891.

Zeng, L.-b., Li, X.-1., Zhang, L., Xu, J., Zhang, Y., 2009. Establishment and characterization of a cell line derived from kidney of channel catfish, Ictaluris punctatus. Journal of Fishery Sciences of China 1, 012.

Zeng, Q., Liu, S., Yao, J., Zhang, Y., Yuan, Z., Jiang, C., Chen, A . Fu, Q. Su, B., Dunham, R., Liu, Z., 2016. Transcriptome Display during Testicular Differentiation of Channel Catfish (Ictalurus punctatus) as Revealed by RNA-Seq Analysis. Biology of Reproduction (in press). DOI:10.1095/biolreprod.116.138818

Zou, J., Secombes, C.J., Long, S., Miller, N., Clem, L.W., Chinchar, V.G., 2003. Molecular identification and expression analysis of tumor necrosis factor in channel catfish (Ictalurus punctatus). Developmental \& Comparative Immunology 27, 845-858. 
Figure legends

Fig. 1. Phylogenetic analysis of the pro-apoptotic BH3-only proteins. The phylogenetic tree was constructed using the maximum likelihood method with JTT + G+F model and $95 \%$ partial deletion method. The bootstrap values are shown at the nodes.

Fig. 2. Phylogenetic analysis of the bnip subfamily. The phylogenetic tree was constructed using the maximum likelihood method with $\mathrm{JTT}+\mathrm{G}+\mathrm{F}$ model and $95 \%$ partial deletion. The bootstrap numbers at the nodes indicts the bootstrap values.

Fig. 3. Phylogenetic analysis of the multidomain anti-apoptotic proteins. The phylogenetic tree was constructed using the maximum likelihood with $\mathrm{JTT}+\mathrm{G}+\mathrm{F}$ model and 95\% partial deletion method. The bootstrap values are shown at the nodes.

Fig. 4. Phylogenetic analysis of the multidomain pro-apoptotic proteins. The phylogenetic tree was constructed using the maximum likelihood method with $\mathrm{JTT}+\mathrm{I}+\mathrm{G}+\mathrm{F}$ model and $95 \%$ partial deletion. The bootstrap values are shown at the nodes.

Fig. 5. Syntenic analysis of selected bcl-2 genes. (A) badb, (B) bcl213, bid, (C) bcl2114s, (D) bnip1b, (E) bnip2s, (F) bnip3. (G) bcl2s, (H) blc2112, (I) bcl2116. Full gene names were provided in Supplemental Table 1. 
Fig. 6. Differentially expressed bcl-2 genes in intestine at $3 \mathrm{~h}, 24 \mathrm{~h}$ and $72 \mathrm{~h}$ after $E$. ictaluri infection. The expression profiles were determined by meta-analysis of the RNA-Seq datasets. Gene expressions were presented as fold change, only the significantly expressed genes (fold change $\geq|1.5|$, with the total reads $\geq 5$ ) were presented.

Fig. 7. Expression profile of channel catfish bcl-2 genes in gill after $F$. columnare infection at $4 \mathrm{~h}, \mathbf{2 4 h}$ and $48 \mathrm{~h}$. The expression profiles were determined by meta-analysis of the RNA-Seq datasets. Gene expressions were presented as fold change, only the significantly expressed genes (fold change $\geq|1.5|$, with the total reads $\geq 5$ ) were presented.

Fig. 8. Expression profile of channel catfish bcl-2 genes in gill after hypoxia challenge in hypoxia tolerant and hypoxia sensitive fish. The expression levels were determined by meta-analysis of the RNA-Seq datasets. Gene expressions were presented as fold change, only the significantly expressed genes (fold change $\geq|1.5|$, with the total reads $\geq 5$ ) were presented.

Fig. 9 . GeneMANIA predicts the relationship between bnip2 and blp1. bnip2 and blp1 has been predicted to physically interact with each other through multidomain anti-apoptotic protein bcl2 (ENSDARG00000089109), and they also interact with the genes that are significantly changed in expression during the hypoxia stress, including 
bcl2113, mcl1a, bcl2110, baxa, bok. 
Table 1. Summary of Bcl-2 family genes identified from channel catfish genome.

\begin{tabular}{|c|c|c|c|c|c|c|}
\hline Group & $\begin{array}{l}\text { Mammalian } \\
\text { bcl-2 genes }\end{array}$ & $\begin{array}{l}\text { Catfish bcl-2 } \\
\text { genes }\end{array}$ & Gene full name & Accession & $\begin{array}{l}\text { ORF } \\
\text { (\#aa) }\end{array}$ & $\begin{array}{l}\text { Linkage } \\
\text { group }\end{array}$ \\
\hline \multirow[b]{11}{*}{ Pro-apoptotic } & \multirow{2}{*}{ BAD } & bada & bcl-2 antagonist of cell death a & JT341548 & 198 & $\operatorname{Lg} 13$ \\
\hline & & badb & bcl-2 antagonist of cell death b & KU511230 & 145 & $\operatorname{Lg} 5$ \\
\hline & BID & bid & bcl-2 interacting domain death & KU511231 & 199 & $\operatorname{Lg} 4$ \\
\hline & BIK & bik & bcl-2 interacting killer & JT412108 & 149 & $\operatorname{Lg} 20$ \\
\hline & BIM & bim & Bcl-2 interacting mediator of & KU511233 & 221 & $\operatorname{Lg} 6$ \\
\hline & \multirow{2}{*}{ BMF } & bmf1 & bcl-2 modifying factor 1 & JT410268 & 152 & $\operatorname{Lg} 6$ \\
\hline & & bmf2 & bcl-2 modifying factor 2 & KU511235 & 164 & $\operatorname{Lg} 3$ \\
\hline & PMAIP1 & pmaip1 & $\begin{array}{l}\text { phorbol-12-myristate-13-acetat } \\
\text { e-induced protein } 1\end{array}$ & JT347455 & 48 & $\operatorname{Lg} 25$ \\
\hline & PUMA & puma & $\begin{array}{l}\text { the p53 up regulated modulator } \\
\text { of apoptosis }\end{array}$ & JT407711 & 180 & $\operatorname{Lg} 22$ \\
\hline & \multirow{2}{*}{ BCL-G } & bcl2114 (1 of 2$)$ & bcl-2-like protein 14 ( 1 of 2 ) & KU511238 & 208 & $\operatorname{Lg} 4$ \\
\hline & & bcl2114 (2 of 2$)$ & bcl-2-like protein 14 (2 of 2) & JT341698 & 265 & $\operatorname{Lg} 23$ \\
\hline BH3-only & BFK & bcl2115l & bcl-2-like protein 15 like & JT340656 & 147 & $\operatorname{Lg} 21$ \\
\hline \multirow[t]{10}{*}{ proteins } & BCL-RAM & bc12113 & bcl-2-like protein 13 & KU511241 & 603 & $\operatorname{Lg} 4$ \\
\hline & \multirow{2}{*}{ BNIP1 } & bnip1a & $\begin{array}{l}\text { bcl2/adenovirus E1B } 19 \mathrm{kDa} \\
\text { interacting protein } 1 \mathrm{a}\end{array}$ & KU511254 & 226 & $\operatorname{Lg} 18$ \\
\hline & & bnip1b & $\begin{array}{l}\text { bcl2/adenovirus E1B } 19 \mathrm{kDa} \\
\text { interacting protein } 1 \mathrm{~b}\end{array}$ & KU511255 & 189 & $\operatorname{Lg} 13$ \\
\hline & \multirow{4}{*}{ BNIP2 } & bnip2a & $\begin{array}{l}\text { bcl2/adenovirus E1B } 19 \mathrm{kDa} \\
\text { interacting protein } 2 \mathrm{a}\end{array}$ & KU511256 & 449 & $\operatorname{Lg} 18$ \\
\hline & & bnip2b & $\begin{array}{l}\text { bc12/adenovirus E1B } 19 \mathrm{kDa} \\
\text { interacting protein } 2 \mathrm{~b}\end{array}$ & KU511257 & 312 & $\operatorname{Lg} 14$ \\
\hline & & bnip2c & $\begin{array}{l}\text { bcl2/adenovirus E1B } 19 \mathrm{kDa} \\
\text { interacting protein } 2 \mathrm{c}\end{array}$ & JT407749 & 355 & $\operatorname{Lg} 2$ \\
\hline & & bnip21 & $\begin{array}{l}\text { bcl2/adenovirus E1B } 19 \mathrm{kDa} \\
\text { interacting protein } 2 \text { like }\end{array}$ & JT411501 & 333 & $\operatorname{Lg} 7$ \\
\hline & \multirow{3}{*}{ BNIP3 } & Bnip3 & $\begin{array}{l}\text { bcl2/adenovirus E1B } 19 \mathrm{kDa} \\
\text { interacting protein } 3\end{array}$ & JT218129 & 197 & $\operatorname{Lg} 5$ \\
\hline & & bnip3la & $\begin{array}{l}\text { bcl2/adenovirus E1B } 19 \mathrm{kDa} \\
\text { interacting protein } 3 \text { like a }\end{array}$ & JT406133 & 237 & $\operatorname{Lg} 11$ \\
\hline & & bnip3lb & $\begin{array}{l}\text { bc12/adenovirus E1B 19kDa } \\
\text { interacting protein } 3 \text { like b }\end{array}$ & KU511262 & 211 & $\operatorname{Lg} 25$ \\
\hline \multirow{7}{*}{$\begin{array}{l}\text { Multidomain } \\
\text { anti-apoptotic } \\
\text { proteins }\end{array}$} & \multirow{2}{*}{ MCL } & mcl1a & myeloid cell leukemia 1 a & JT407366 & 258 & $\operatorname{Lg} 24$ \\
\hline & & mcllb & myeloid cell leukemia $1 \mathrm{~b}$ & JT411974 & 253 & $\operatorname{Lg} 1$ \\
\hline & BCL-XL & blp1 & B-cell lymphoma-extra large 1 & KU511249 & 242 & $\operatorname{Lg} 15$ \\
\hline & \multirow{2}{*}{ BCL-2 } & $\mathrm{bcl} 2 \mathrm{a}$ & B-cell lymphoma 2a & JT400297 & 204 & $\operatorname{Lg} 19$ \\
\hline & & $\mathrm{bcl} 2 \mathrm{~b}$ & B-cell lymphoma $2 b$ & KU511251 & 204 & $\operatorname{Lg} 8$ \\
\hline & BCL2L10 & bcl2110 & bcl-2-like protein 10 & KU511252 & 178 & $\operatorname{Lg} 4$ \\
\hline & BCL2L12 & bc12112 & bcl-2-like protein 12 & JT341893 & 363 & $\operatorname{Lg} 3$ \\
\hline Multidomain & \multirow{3}{*}{ BAX } & baxa & bcl-2 associated $X$ protein a & KU511242 & 112 & $\operatorname{Lg} 3$ \\
\hline \multirow{4}{*}{$\begin{array}{l}\text { pro-apoptotic } \\
\text { proteins }\end{array}$} & & baxb & bcl-2 associated $X$ protein $b$ & JT406892 & 202 & $\operatorname{Lg} 3$ \\
\hline & & baxl & bcl-2 associated $X$ protein like & KU511244 & 203 & $\operatorname{Lg} 20$ \\
\hline & BOK & bok & bcl-2 related ovarian killer & JT409073 & 214 & $\operatorname{Lg} 7$ \\
\hline & Not present & 1 & bcl-2-like protein 16 & JT410195 & 199 & $\operatorname{Lg} 11$ \\
\hline
\end{tabular}


Fig. 1

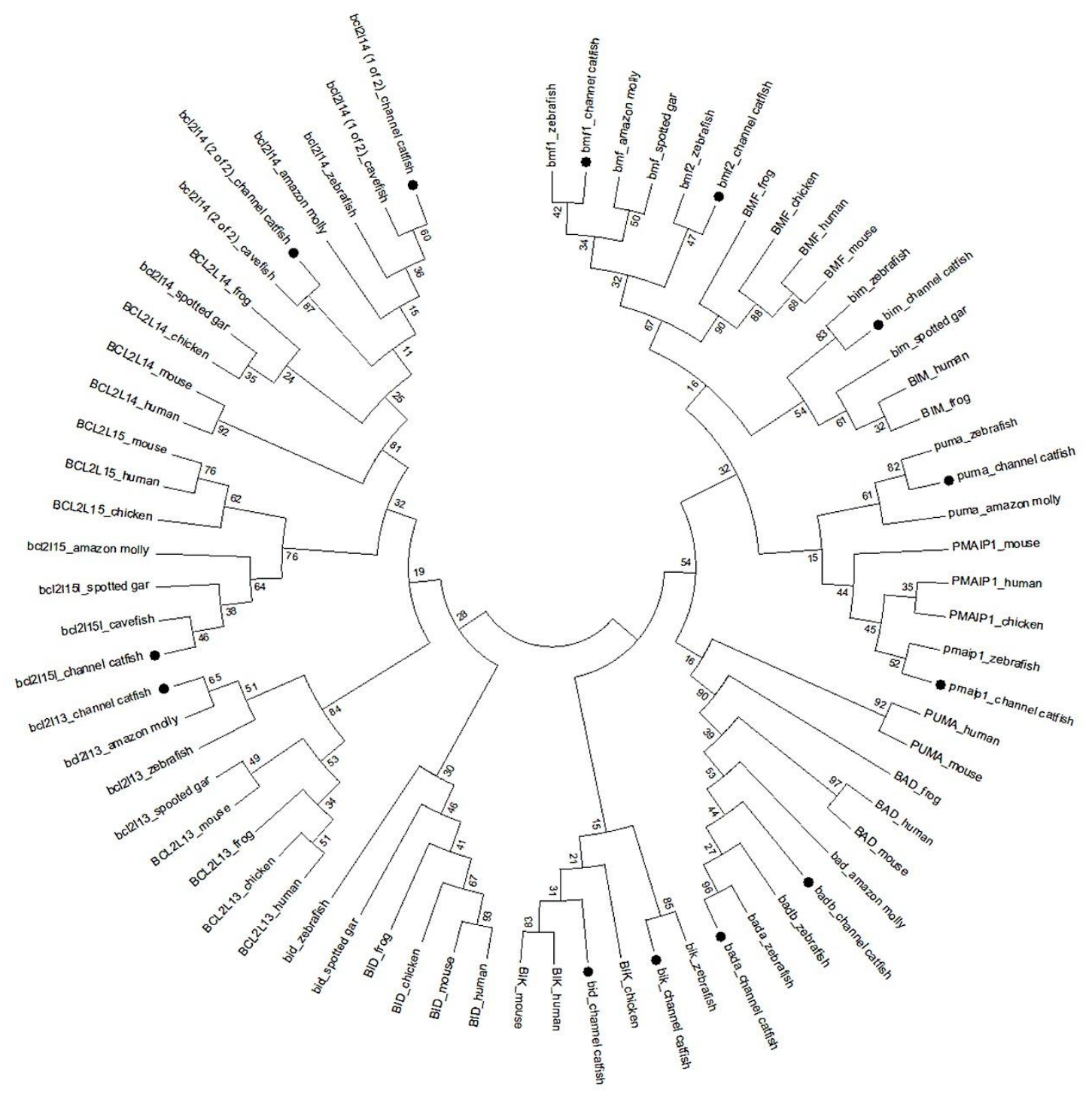


Fig. 2.

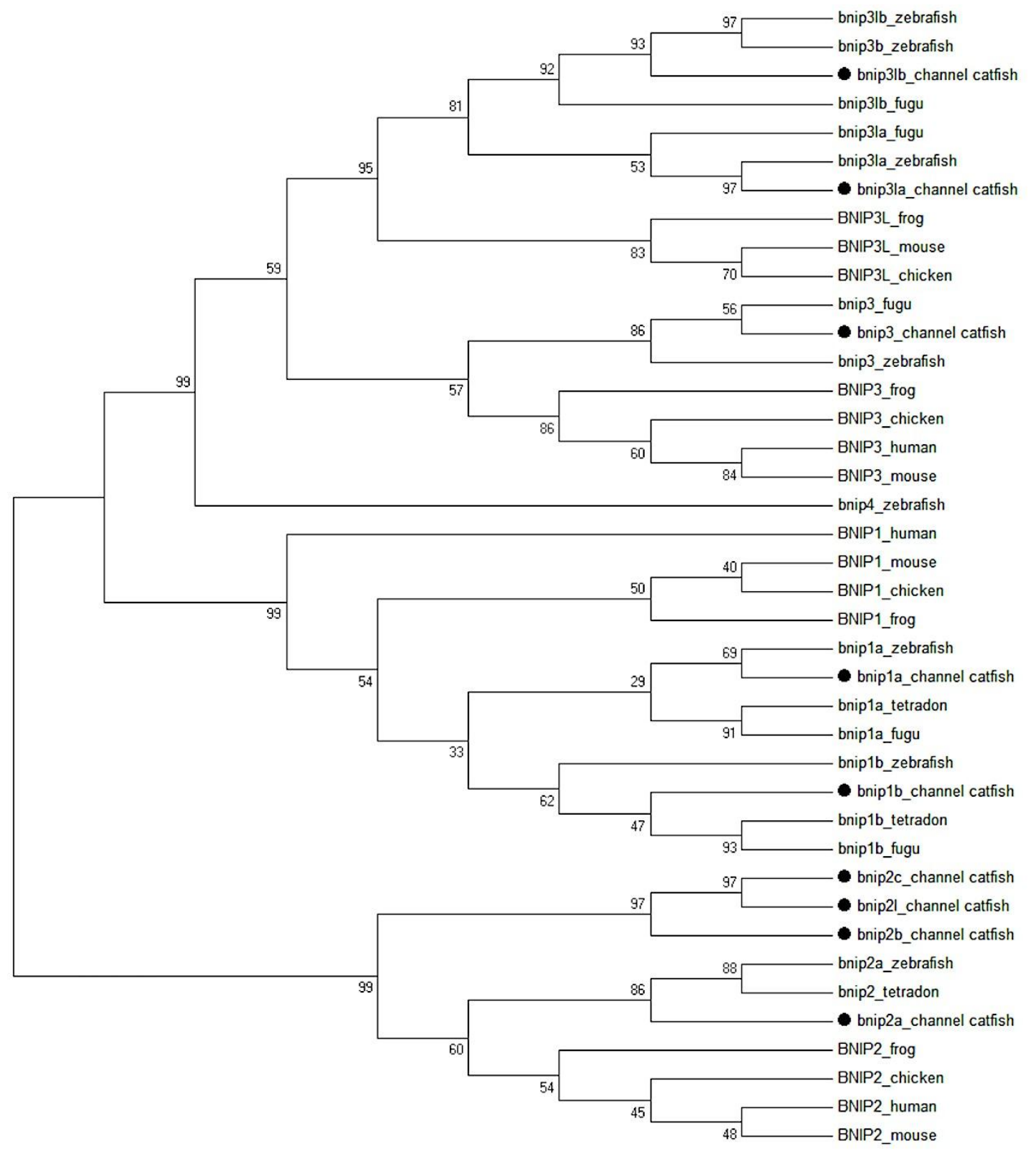


Fig. 3.

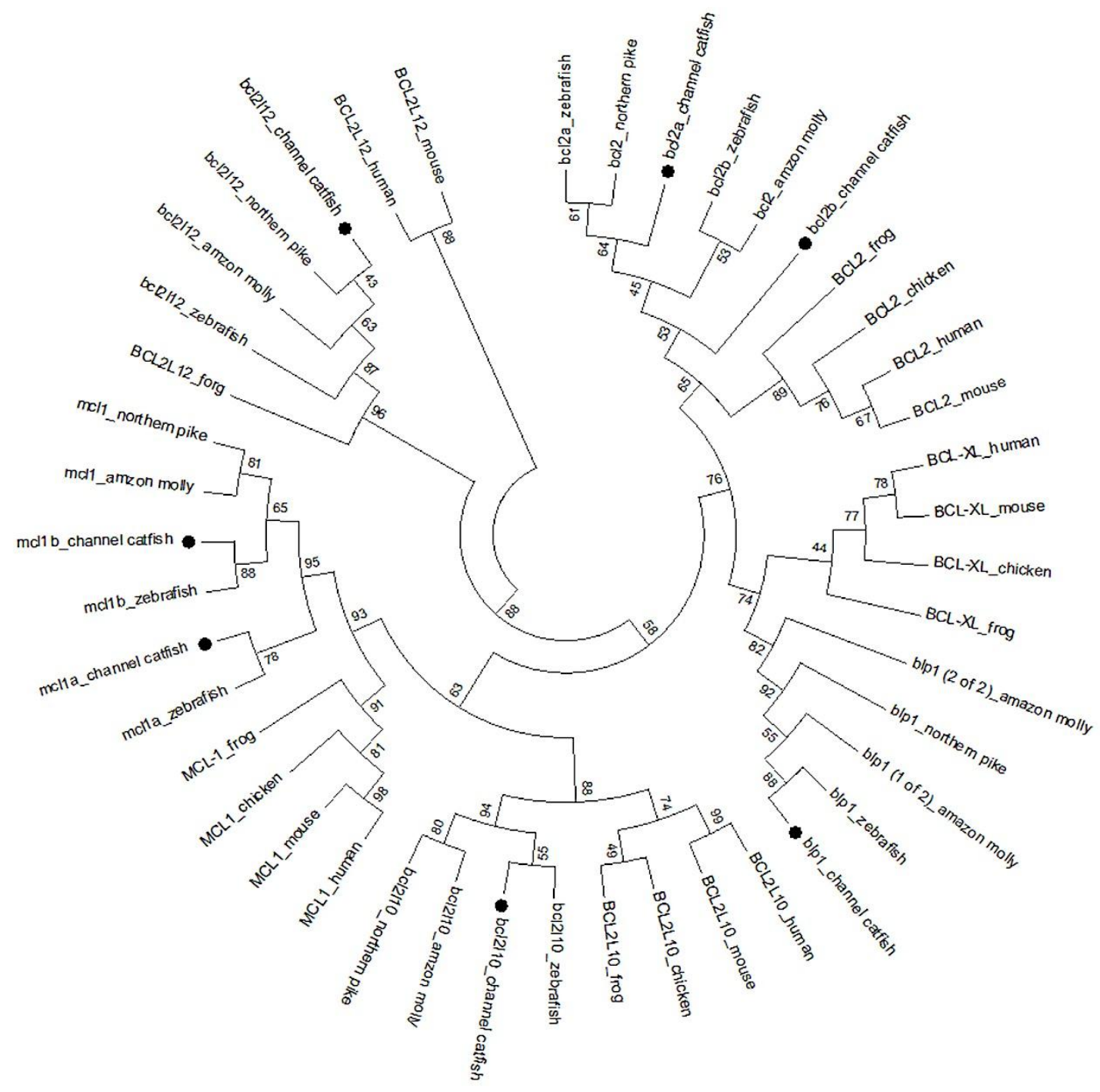


Fig. 4.

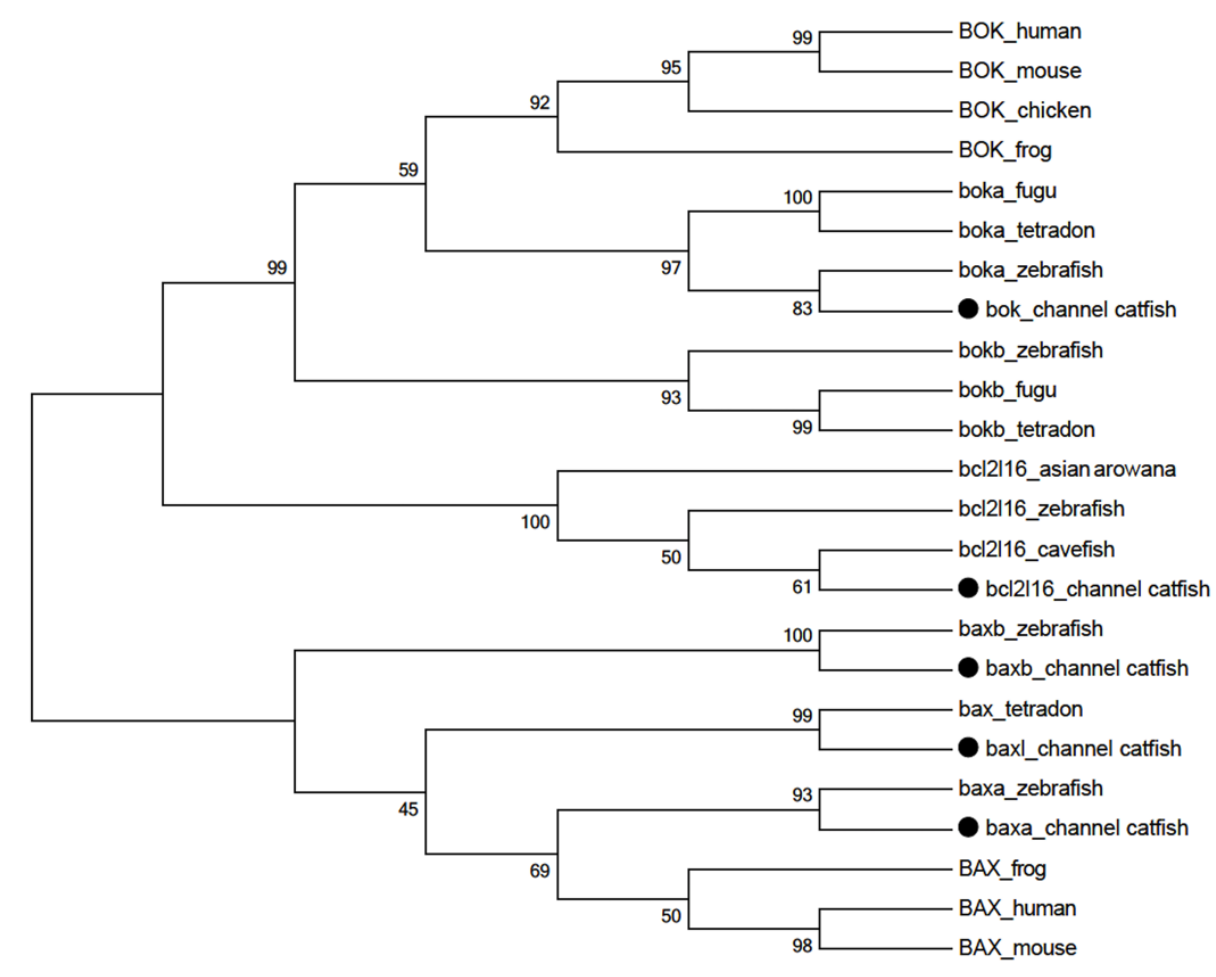


Fig. 5.

A

Zebrafish

Chr7

b3gat3 - arl2 - ppp2r5b-gpha2 - exoc6b - cyp26b1 -

Channel catfish LG5 (jcf7180014892033)

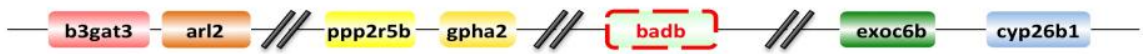

B

Human

Chr 22

हC12는

Zebrafish

Chr 18

Channel catfish

LG4 (jcf7180014891998)

cftr - asz1

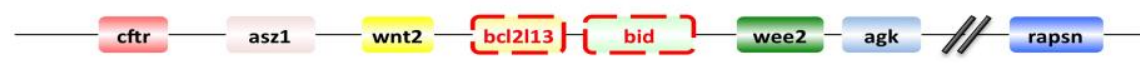

C

Zebrafish
Chr:4

Chr:4

Cavefish
Chr:KB882123.1

Channel catfish

LG4 (jcf7180014890888)

Cavefish

Chr:KB871620.1

Channel catfish

LG23 (jcf7180014891089)

D

Zebrafish

Chr21

Channel catfish

G13 (jcf7180014892126)

E

Zebrafish

Chr25

Channel catfish

LG18 (jcf7180014891991)

Channel catfish

LG14 (jcf7180014892102)

Channel catfish

LG2 (jcf7180014892003)

F

Zebrafish

Chr12

Channel catfish

LG5 (jcf7180014892033)

G

Zebrafish

Chr24

Channel catfish

LG19 (jcf7180014891947)

Zebrafish

Chr2

Channel catfish
LG8 (jcf7180014892044)

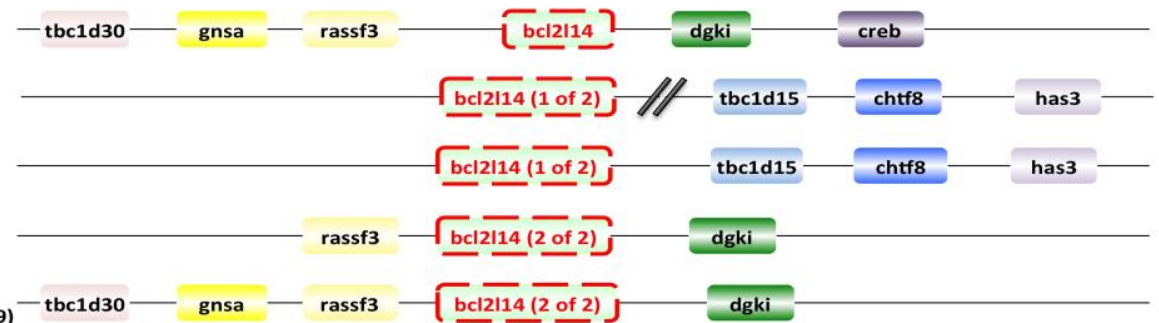

LG8 (jcf7180014892044)

H

Zebrafish

Chr3

Channel catfish

LG3 (jcf7180014891469)
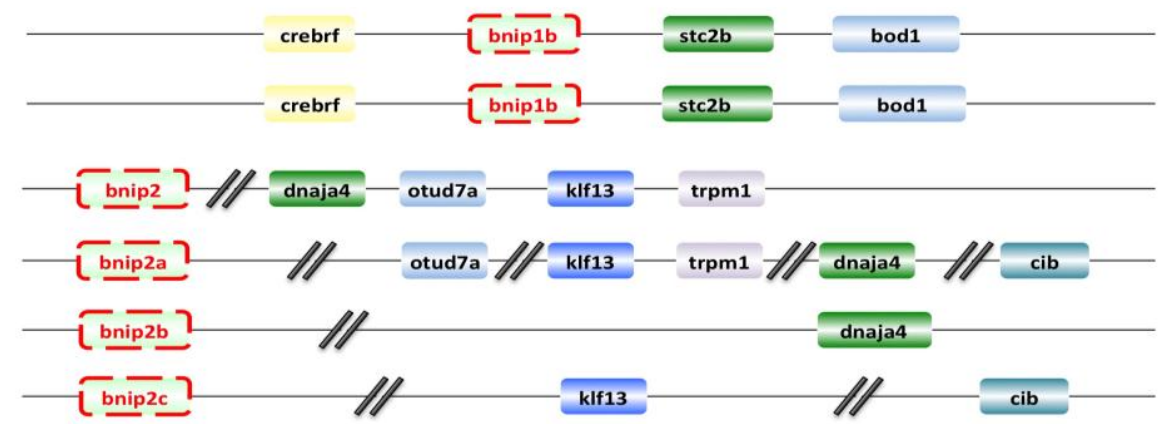

Zebrafish

Chr8

Channel catfish

LG11 (jcf7180014892218)
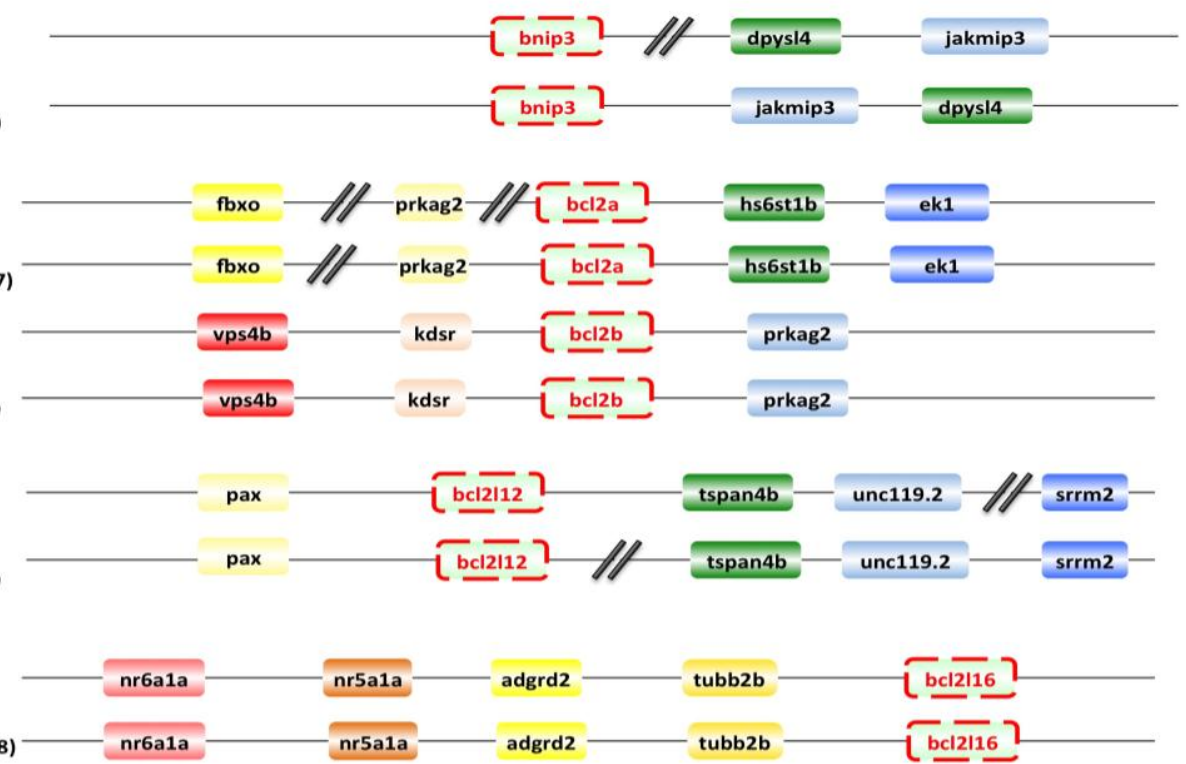
Fig. 6.

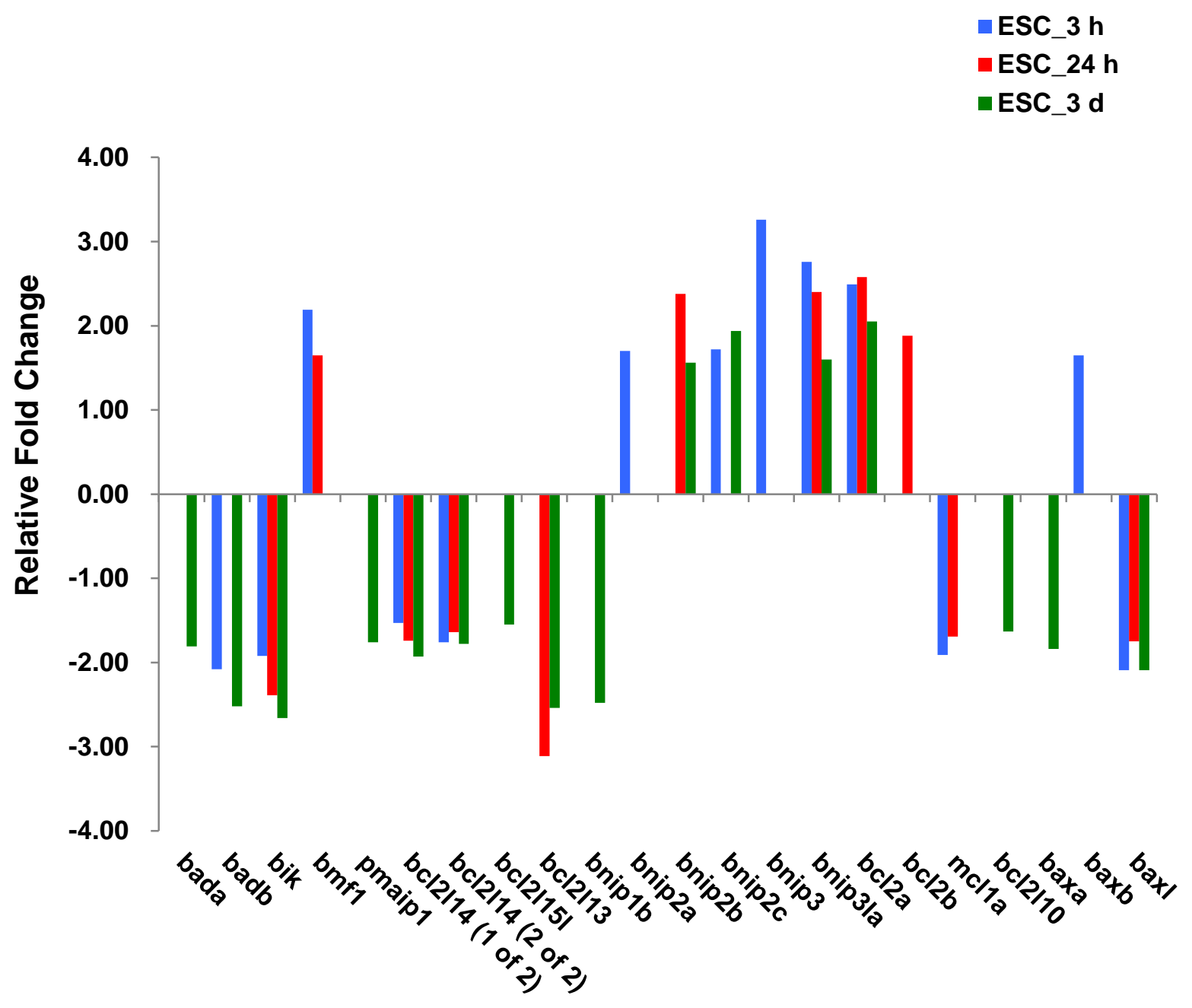


Fig. 7.

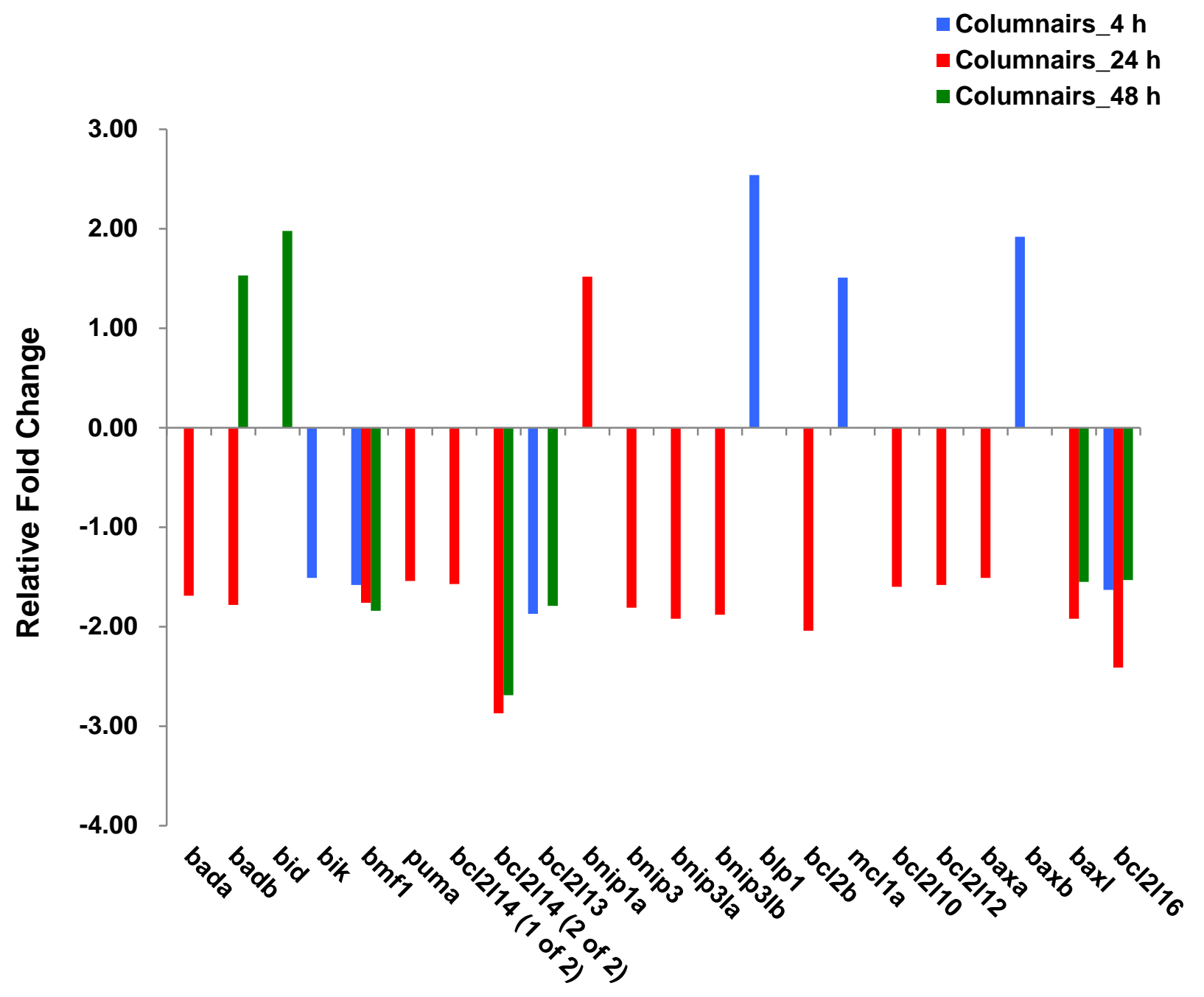


Fig. 8.

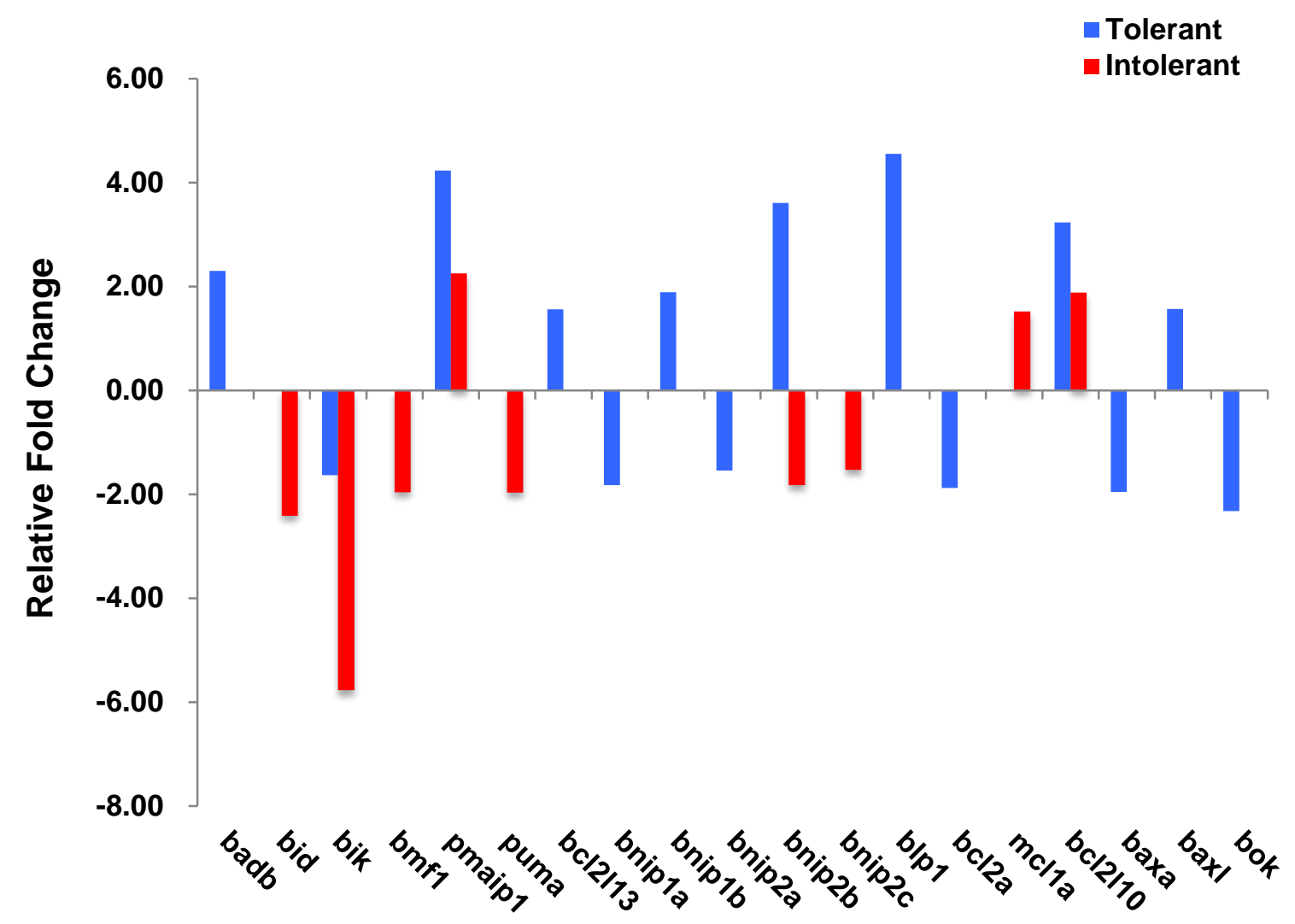


Fig. 9.

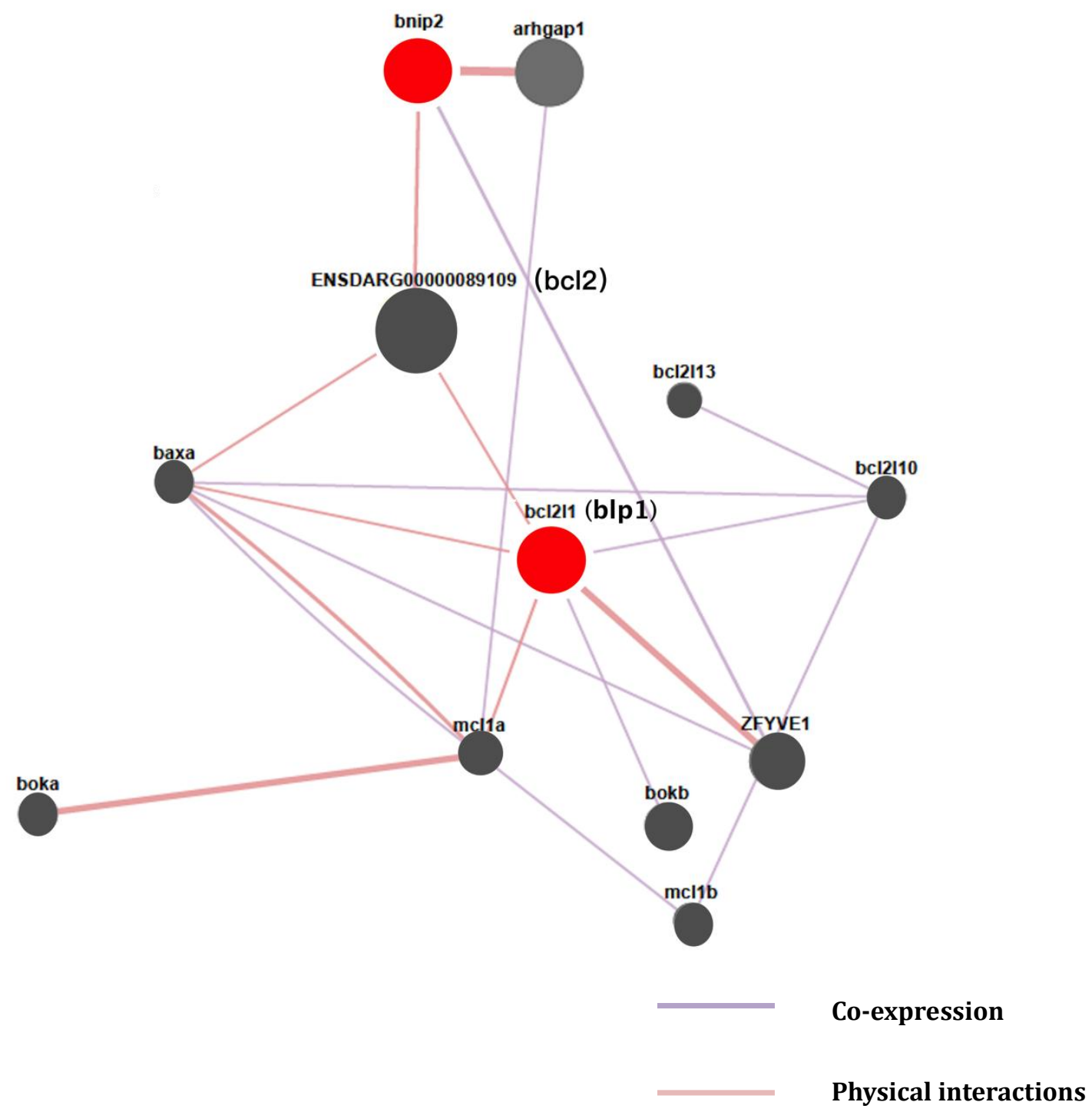

